\title{
Research Library Collections in a Changing Universe: Four Points of View
}

\author{
Pauline Atherton Cochrane, Oscar Handlin, \\ Hendrik Edelman, and William Herbster \\ Compiled and edited by \\ Dan C. Hazen and J. Gormly Miller
}

In 1977 the Cornell University Libraries received an Andrew W. Mellon Foundation grant to study collection development and management. The immediate concern was to develop and test techniques that would allow Cornell's libraries, and academic libraries in general, to control their collections and collecting costs in a period of financial crisis. The "Cornell University Libraries' Project for Collection Development and Management" (or the "Mellon Project," as it came to be known), experienced shifts in both emphasis and personnel over time. Project Director J. Gormly Miller's Collection Development and Management at Cornell: A Concluding Report on Activities of the Cornell University Libraries' Project for Collection Development and Management, July 1979-June 1980, with Proposals for Future Planning. Prepared under a Grant from the Andrew W. Mellon Foundation (Ithaca: Cornell University Libraries, 1981) offered general and specific suggestions concerning the collection development process. The report's broadest conclusions, which addressed the role of the research library and library collections in the university of the future, became the focus of a half-day seminar held on the Cornell campus early in April 1983. This seminar was organized so that each participant commented on the role and mission of the university research library, and on the organization of information resources networks within universities, within the context provided by the Concluding Report.

\section{PAULINE}

ATHERTON COCHRANE

Professor Cochrane focused her comments on the appropriate role of the academic research library in the contemporary information environment. Her thematic reference point was the dedication ceremony for Cornell's Olin Library, twenty years before.
The past two decades have indeed challenged librarians. The University of Toronto initiated its automated catalog, now known as UTLAS, in the same year as the Olin dedication. The Library of Congress began distributing MARC tapes fourteen years ago, when Lockheed also inaugurated the Dialog literature search service. Channel 2000, a home-based interactive

Pauline Atherton Cochrane is professor, Syracuse University School of Information Studies; Oscar Handlin is professor and director of libraries, Haroard University; Hendrik Edelman is university librarian, Rutgers University; and William Herbster is senior vice president, Cornell University. Dan C. Hazen is visiting curator for the Latin American Collection, Stanford University; and J. Gormly Miller is former director of libraries, Cormell University. This paper has been reviewed and approved by each of the four participants with the understanding that it was being prepared for publication in C\&RL. 
information system in Columbus, Ohio, began offering banking services, access to the public library catalog, announcements of local interest, and the like, three years ago. The Chicago Public Library inaugurated an informational database, detailing local events and other timely information, two years ago. And only this spring the Library of Congress unveiled its exhibit on the American cowboy, which includes an optical disk as an integral component. LC is also exploring disk applications for preservation, and has created interactive disk programs to instruct users about its online catalog.

This skeletal chronology of technological change allows several generalizations. First and foremost, technology has indeed impinged upon information and upon library services. Speakers at the Olin Library dedication stressed the need for cooperative support for the country's then-burgeoning area studies collections. Automation, phrased as the "pushbutton library," was scarcely mentioned. We have since experienced a telecommunications revolution, and the old assumption that books (perhaps augmented by film) would forever remain the principal medium for storing and transferring information is no longer viable. The library profession, in other words, must be concerned with the development both of collections per se, and of mechanismsdatabases and interfaces-to link and provide access to information.

The contemporary environment has been shaped by the following circumstances:

1. Information services and links within the library can be employed to connect users to information sources located outside the library.

2. The bibliographic and substantive information services which libraries offer can, conversely, be consulted at remote locations. Nonetheless, the books remain in the library. Can library holdings themselves be made as easily available as information about them?

3. Libraries are creating their own information resources, and are electronic publishers in their own right. The RLIN and OCLC databases, for instance, are really electronically published catalogs. The Library of Congress has established a direct link with Harvard, whereby Harvard will add its cataloging copy to the MARC database. In even broader focus, the "Linked Systems Project" will provide access to RLIN, WLN, and LC, and will allow users to switch between the databases and to search all the authority files. Such cooperation may minimize the impact of cataloging cutbacks at LC, as well as fulfilling libraries' growing potential as electronic publishers.

4. Librarians continue to mediate between their immediate clientele and information resources. Increasingly, though, they are also linking distant users with their services and resources.

These trends are attracting ever more attention. The National Library of Medicine, for instance, has solicited proposals from academic medical libraries to develop an "integrated academic information management system." A recent report from the Association of American Medical Colleges highlighted technology's potential to transform medical libraries and information by integrating them within a general information system. This kind of system could provide ready access to such divergent data as test results, the medical literature, bibliography, patient histories, and billing information. The possibilities are clear, though the role of the academic medical library in realizing them may be less so.

Other educational institutions are similarly concerned with the role and potential of electronic technologies. A meeting on "The College Enters the Information Society," held earlier this spring, focused on how libraries will function within the "wired" academy. Will libraries act as "switching points" between the multiple information nodes characterizing these institutions? While this mediating function would be somewhat new, it will also be an increasingly necessary response to the developing environment of electronic information.

The extent to which new technology has pervaded academia is also reflected in still-tentative efforts at electronic publishing. As early as 1961, the American Insti- 
tute of Physics envisioned journals that would incorporate online peer review. Many scientific reports, comprising the so-called "grey literature," are now prepared electronically. Scientists do use these materials, and database suppliers and retrieval system vendors have taken the lead in providing them. Librarians, too, need services that will link this electronic literature with our book collections. Nuclear Science Abstracts tracks the reports accessible to the Atomic Energy Commission and records their eventual publication in printed journals. In this case, report literature is documented both as originally submitted and in its fully assimilated, published form. On the other hand, not all fields are embracing-or being embraced by-technology with equal dispatch. A draft report on circulation patterns at Virginia Polytechnic Institute has revealed very different patterns of collection use between types of material and users and disciplines. The humanities, for instance, will almost certainly be among the fields last affected by the electronic revolution.

Collection development must reflect the process and progress of information transfer in all areas of knowledge. Online data constitute a new link in the chain of knowledge. Library users are aware of this information, and they want libraries to respond to their needs. Academic libraries must thus expand their approach to information resources in order to meet their users' widening expectations.

Enhanced access will not only involve traditional collection development, with its implicit corollary of physical access to information resources, but also intellectual and bibliographic access to information per se. User requests must be matched with information, however that information happens to be packaged. Changing the terminology, libraries must assume the function of maintaining and providing addresses for warehoused information in all forms. One example is on- line library catalogs which, right now, integrate in-house bibliographic data with circulation information: both the existence and the location of a work can be determined. Collection management is another area in which the developing electronic environment may have a major impact, though here the effects have yet to be addressed.

In sum: Stephen McCarthy's remarks at the Olin Library dedication emphasized that Cornell seeks to create a unity out of its multiplicity and diversity, and that the library should echo this goal. An information resources network, drawing fully on the possibilities of contemporary technology, will similarly enhance a sense of common purpose and a degree of order. Herein lies our future.

\section{OSCAR HANDLIN}

The academic research library is a library dedicated to research and located within a university that both establishes its context and limits its autonomy. The academic research library justifies its existence through its relationship with the university.

Within the university, then, the research library devotes itself not to the mere accumulation of books, but rather to the development and maintenance of collections. Its proper terms of reference are its constituent collections, not the total number of titles or volumes that it may possess. This focus on the collection has been complicated by such pernicious fantasies of academic life as "I would found an institution where any person can find instruction in any study." + Good-hearted though they are, such declamations are entirely misleading. The university is limited in the fields that it can support and in the persons that it can accommodate. So is the research library limited: it cannot and should not seek to provide any book in any subject for anybody. Rather, the academic research library should focus on

\footnotetext{
*Stephen A. McCarthy was Cornell's director of libraries from 1946 until 1967.

tA quote from Cornell's founder, Ezra Cornell, which has been immortalized as the university's motto.
} 
tightly defined areas of interest that somehow relate to the university's work and aspirations.

Academic research libraries can follow several courses in attempting to develop collections relevant to the university's research needs. One approach is to monitor current research interests by consulting with faculty members and students and to construct acquisition policies designed to satisfy these immediate needs. This approach guarantees disaster. Building collections to satisfy current demand is building them too late, and librarians must instead anticipate the research interests of twenty years hence. To cite a concrete example, Harvard and the New York Public Library began collecting Russian materials in the 1920 s, when no one else was interested. These collections remained virtually untouched for years. But when the field of Soviet studies did emerge, in the 1940 s and 1950 s, early materials were no longer available, and the Harvard and NYPL collections proved invaluable.

Deaccession is also an integral part of the library dynamic. Harvard removes about 45,000 volumes each year, though this process focuses on volumes rather than collections, and emphasizes outdated instructional texts, duplicates, and the like. Collecting ventures are occasionally suspended, as when Harvard relinquished its incipient efforts in Africana. The process is continuous, but also problematic. Thus, for instance, Harvard has built the world's preeminent collection on Islamic law, but no one in its law school is using these materials. The collection has value by virtue of its existence, and Harvard may have thereby incurred an obligation to the Western scholarly community to maintain it. But law library users would rather have another terminal for online information, and future funding arrangements for the Islamic collection are unclear. An appreciation of the collection's long-term worth must at least partially offset the clamor of immediate concerns.

As the above-cited example of Soviet studies may suggest, the "magic" in creating research collections derives from specialists who can make educated guesses for the future. Adequate re- sources are likewise essential. Where inadequate funding precludes the implementation of specialist insights, the library will fail as certainly as if its selectors focus on inappropriate material. There are no shortcuts, and no formula will allow the research library to maintain its stature. The conjunction of scholar-bibliographers and dollars is indispensable for success.

Even as libraries require funds to develop their collections, then, library budgeting remains intractable to the logic of accountants. Were libraries conceived of as economic enterprises, then acquisitions budgets would represent capital outlay. Books, at least for the purposes of this illustration, not only do not wear out, but tend to appreciate over time. If university administrations were persuaded of this analysis of bibliothecal appreciation, then libraries would be seen as carrying immense unrealized profits, and balance sheets would be adjusted accordingly.

However, libraries are not created as investments, so this perhaps seductive logic does not hold. Some things in life simply are not susceptible to balance-sheet reductionism. Libraries can and should live within budgets, but books and collections cannot be costed out in a "normal" fashion. Part of the answer at Harvard has centered on library endowments, which now total more than $\$ 50$ million. A side benefit to endowment funding, then, is that the entire community has become sensitized to the library's importance.

Libraries, even in research universities, are not just homes for research collections. They are also places where information is available. In the research context, though, it is essential to distinguish between research collections and information. Information is data of whose existence a user is aware, and is the object of a closed and circumscribed search. Research, by contrast, is an open-ended process of definition in which the goals may remain unclear until the very end. Information is available in many forms, of which only some are housed within the library. Information is also essential, but it is fundamentally different from the library collections that support research. Technology can help make information more accessible; such 
hard-copy compilations as telephone books, statistical abstracts, or encyclopedias in fact are relics of our past reliance on paper.

As information does become more portable and more accessible, it becomes ever less appropriate for the research library. Information is essentially a "large but inert" body of material, for which the terminology of warehousing is entirely appropriate. Neither the vocabulary nor the underlying concepts of warehousing, however, can apply to research collections, since the research process is so fundamentally different from information gathering. The retailing and brokerage of information can and must be distinguished from collection development in a research library. In fact, information databases and exchange points might be most appropriately sited in public libraries, where all could benefit. Alternatively, free-market access through commercial ventures like Channel 2000 might ensure a more equitable and efficient distribution of this commodity.

Whatever the solution, the university research library should not attempt to provide information as well as to maintain research collections, even though most academic libraries try to do both. Library facilities geared to instruction, and to the provision of information, are now quite commonly tied to research libraries. Such arrangements embody a clash of function that inevitably distorts the process of allocating resources. Instructional libraries are highly visible, and their needs are pressing. The future-oriented priorities of research collections tend to be relatively invisible and are thus more easily shortchanged. Over time, the tension between information and research functions inevitably works to the detriment of research collections.

Many scenarios for the future anticipate an era of electronic publishing. However, the process as advocated by its more radical proponents-in which everyone's data, discoveries, and insights would be accessible online-omits any component of peer review. Information disseminated in this manner, without quality control, would only amount to "static"; and an overabundance of static makes any information, or information system, unusable. If some research finding or bit of information has value, it will work its way into the literature. Furthermore, even researchers in fields purported to require speedy access to new findings, for example physics, may not really require the instant access so often assumed. Close analysis may prove both the importance and the convenience of immediate electronic information somewhat fictitious.

Electronic technologies, while wonderful (and expensive), thus do not address the research process. Unless university libraries are confident that they can both maintain their existing and generally "feeble" efforts to create research collections, and assume new functions as well, the research function will suffer. Professor Handlin would therefore bless any effort to divorce information services from the library. Herein lies the way to free the academic research library to accomplish what it alone can: that is, to maintain the scholarly collections of mature, durable research products that the research university requires to survive.

\section{HENDRIK EDELMAN}

Mr. Edelman's presentation reflected his various professional perspectives visà-vis the Mellon Project, including those of the project's first director, library administrator of Cornell, positions within Rutgers and RLG, and library school professor. This variety of experience was used to explain some of the historical and insitutional contexts for the Mellon Project at Cornell.

Postwar growth in American higher education, after several decades of boom, ground to a halt around 1969. Cutbacks in educational funding, to considerable extent mandated by circumstances exogenous to the academic world, led to a virtual state of depression in the early 1970s. Publishers, who were not well attuned to their market, continued to flood a shrunken academic sector with new materials even when the books could not be absorbed. These circumstances led to an experience that was new for all concerned. 
Libraries, flush with ever-larger budgets and acquisitions programs, had been regarded as successes throughout the 1960s. By the mid-1970s, in a notable irony of interpretation, university administratorsand librarians themselves-saw libraries as problems. This perception was augmented insofar as academic librarians at the time could neither explain nor control what was happening. University libraries were regarded as bottomless pits, and academic administrators too-often succumbed to the temptation to cut acquisitions budgets in order to slow their libraries' incessant demands for ever more books, space, and staff.

It was within this depressed context that Cornell proposed to study collection development. Even as the Mellon Project got underway, though, the environment again changed: the period of acute crisis was fairly short. One of the most significant shifts involved the quantity of new publications. Publishers adjusted to smaller markets, and there was an overall decline in world publishing output-albeit the reductions have concentrated in reprint, microfilm, and humanities materials, while scientific publishing continues to expand and the international market follows any number of diverse local dynamics.

A second major change has been our increased bibliographic capability, within which the selection and identification potentials of a tool like RLIN's acquisitions subsystem are critical. The Library of Congress has acknowledged that it cannot and will not catalog everything it receives. The cutback is permanent, and the research library community must cover the loss. Online bibliographic databases have helped create a de facto distributed operating mode among the nation's libraries which, for full catalog records, has existed for some time. However, as the time between when items are ordered and when they are fully cataloged increases, and as cutbacks within LC make it impossible to rely on MARC tapes or proof cards for selection, interim online records will become ever more important. If acquisitions data comprise the only available bibliographic information, then these records must be shared for effective collection development. Both identification and selection functions can thus be enhanced by new electronic technology.

A third area of change is that we know much more about our collections than ever before. Studies like those conducted during the Mellon Project, as well as efforts at other institutions, have enabled us to define and describe collections with unprecedented precision. In a context like Rutgers, which is highly dispersed and which suffers from a substantial communications problem, collection analysis has permitted a reorganization of selection responsibilities and resources. On the "macro" level, this analysis has permitted a careful definition of collecting responsibilities throughout the system. At the "micro" level of specific purchases, online acquisitions information means that units can immediately determine whether another unit has ordered an item that is of some interest but which does not fall within their primary collecting categories. The combination of better-defined collections, and quick access to order information, also enables closer library contact with users. Public service functions, as well as selection, acquisitions, and cataloging, are more efficient and more effective.

Increased knowledge of collections has also refined our understanding of the possibilities and the limitations of cooperation. It has always been apparent that cooperation will not reduce costs. However, cross-collection comparisons suggest that the overlap between similar collections at different locations may be lower than librarians once assumed. Within Rutgers, for instance, two collections of Puerto Rican literature built in units with similar resources and goals show very little overlap. The collection development process at different institutions may well not generate essentially duplicate collections.

One practical result of this apparently low overlap between ostensibly similar conditions is that Rutgers is not participating in the Research Libraries Group's assignment of priorities for cooperative collection development. Analyses like those cited above, or like Cornell's studies of the 
nationwide availability of Southeast Asian materials, demonstrate that collections are in fact interdependent. The RLG conspectus exercise has served to identify some weak areas, which the research library community can strengthen through cooperation. In the future, particularly, cutbacks in foreign language acquisitions are a real threat. However, neither the history of cooperative efforts, nor the bureaucracy that a national plan is likely to entail, bodes well for a permanent solution. Of greater immediate importance, our growing awareness of collecting realities belies the notion that any one library might anchor the nation's holdings in some field. No single collection can be either sufficient or definitive.

A fourth and final change, which has affected virtually all academic institutions, centers on increased accountability. Greater attention to student concerns, for instance, has added complexity to the library selection process. Users must be kept satisfied as a matter of political survival. On the other hand, just as the overall growth in American higher education has slowed or stopped, so have specific institutions sought to limit the emergence of new programs: increased accountability is affecting the rise of new academic endeavors. Nonetheless, interdisciplinary programs continue to cause problems for both library collection development and administration. Furthermore, many university administrations still fail to adjust library book budgets in response to the needs of new academic programs, and resource allocation is an issue yet to be fully addressed by either library or university administrations. Budgeting models for the distribution of computer time, or for access to electronic databases, may provide insights for library funding structures-though we must beware of only providing information to those who can pay for it. At Rutgers, programmatic accountability vis-à-vis the library is ensured insofar as Mr. Edelman's signature is required before new academic programs can be implemented. The library has a direct voice in the process of allocating for expansion.

These four broad areas of change-shifts in the overall context of higher education, increased technological capabilities, better knowledge of our collections, and greater accountability within universities-have transformed the environment of the research library. The electronic revolution has played a role. However, it has not altered the basic parameters within which libraries operate, and we must be wary of the mythology of total technological transformation in some more-or-less immediate future. Electronic technologies, for instance, remain extremely expensive: hard-copy pages from one electronic journal cost fifteen dollars apiece.

The publishing industry has already adapted to new technology. Electronically assisted editing and composition are commonplace, but pages are still the end product. And pages will probably remain the end product, even though high printing costs and small markets make much academic publishing only minimally profitable. Since peer evaluations remain fundamental to the review structure for faculty tenure, wholesale shifts toward the unfettered exchange of unscreened information are unlikely. Perhaps more significant in their immediate impact on libraries are archival collections, which are experiencing extremely rapid growth. The microform "disaster" of the past twenty years, on the other hand, suggests that the value of the text does indeed prevail over the utility of its format. (Thankfully, microform is now generally recognized as only an interim storage medium. New technology, like video disks, should bring a more satisfactory solution to the needs of storage and preservation.) We can and should speculate about the electronic future, but this should not defer action on immediate and urgent problems. To date, the basic issues of collection development have been only peripherally affected, or addressed, by the electronic revolution.

Various Mellon Project methodologies have been applied at Rutgers. One major accomplishment was to describe each collection, in a process that allowed the collections to be redefined, relocated, and priced. The library has tied its local collections more closely to their immediate academic constituencies, and in so doing has 
created user advocates, increased its accountability, and reaped political benefits. The political dimension bears particular attention: library budgets simply cannot meet all needs, so special attention must be given to those who care the most. Rutgers has found it difficult to justify special documentation projects within the library system, particularly since many of these were originally funded from outside sources. Some such projects have been returned to the academic units from which they originated, though the library has retained bibliographic control. In fact, Rutgers now functions as a decentralized information network with central bibliographic control.

Turning to Cornell, the university administration has, since the 1960 s, fallen consistently short in its support of the library. There have been no capital investments in the book budgets, and the library has fought a protracted and losing battle to sustain its purchasing power for acquisitions. Neither have adequate capital investments been forthcoming for library space, or retrospective collection development, or technological improvements, or preservation. Such investments must be made, and they must be made in full knowledge that technology is not a cost saver for research libraries. Private universities have developed convincing cases to attract foundation support for their research libraries. These capital infusions are all to the good, but internal funds are needed as well. Discussions between the head librarians of different universities are likewise commendable, but they will not reduce costs. The cooperation that results from these conversations may help make the best of mutual shortages, but it cannot generate savings.

On the other hand, some budgetary concepts and mechanisms once thought scandalous are now quite generally accepted. Ronald Reagan, as governor of California, created an uproar by declaring that the state university could solve its budget problems by selling its rare books. Today, in fact, most libraries do sell off materials-including rarities-as a matter of course. At many smaller institutions, out-of-scope collections have been sold wholesale. Such sales also reflect the process of tuning collections to meet both library possibilities and user needs. As recent shifts at the New York Public Library suggest, the reassessment of collecting efforts may have dramatic results.

To sum up: the electronic revolution has generated many unrealistic expectations, despite its proven utility for some information-related functions. Technology simply cannot address all aspects of the library environment. The increasing accountability of both libraries and universities, for instance, is peripheral to technological change. The issue of centralization versus decentralization remains crucial, and overlap and duplication are an inevitable cost of decentralization. Decentralization on a national scale requires the same sensitivity: interlibrary loan programs are no substitute for local acquisitions, particularly at an isolated institution like Cornell.

We cannot ignore present needs by dreaming of some cheap fix for the future. Change will certainly occur, but in the meantime we must confront pressing needs for traditional materials, and also cope with the past's legacy of crumbling paper. Increased funds are essential.

It remains unclear whether the academic library either is, or should become, the hub of a comprehensive information network. In an institution like Cornell, no single individual or unit will ever have control over all information. Moreover, the coordination of information resources is basically a problem of university management. While the appropriate locus for university initiatives to address the coordination and/or control of information resources will vary between institutions, the basic mandate will have to come from the top. Some universities have designated a vice president for information, though this response encourages bureaucratization and inflexibility. On the other hand, the library has very little political power: it is responsible to all, and even its authority to select books is challenged every day.

Librarians can and should play a role in establishing an information network, but the information brokerage function is not part of the library's current mission, and 
any such new responsibility must be accompanied by increased funds. Furthermore, few academic libraries are prepared to undertake research functions, and few provide rewards to those staff members who engage in such activity. Additional layers of work and responsibility simply cannot be indefinitely superimposed on an already busy staff. The library might very well be an appropriate source of innovation and leadership in addressing the utilization and control of information, but rewards must be provided.

\section{WILLIAM HERBSTER}

Mr. Herbster opened his presentation by recognizing the importance of research libraries within both the university and our knowledge-based society.

Nonetheless, such appreciations must be balanced against the constant calls for Day Hall administrators to reorder their priorities, and thereby increase support for particular Cornell functions. * These often-strident demands come at a time of diminishing real resources, in an era that has been typified as one of "the management of decline," or "creative frugality," or "aggressive withdrawal." Cornell's total capital needs for the next decade, under all rubrics, could reasonably exceed half a billion dollars. These funds will not be forthcoming, so cuts and compromises are essential. The context is one in which economics are fundamental, and administrators, scholars, and librarians should share the common goal of developing data that will ease the task of finding new resources.

The Mellon Project's emphasis on integrated planning is particularly useful within this context of restraint. As Professor Handlin asserts, the library is building for future research. Collection development must be adapted to the overall planning process as well as to new patterns of information utilization.

More and more knowledge is also being created and stored outside the library. The academic library must explicitly address the trade-off between actually acquiring information, and providing the fullest possible access to all knowledge and information, whether available locally or somewhere else, and whether housed in libraries or museums or on tape. In other words, the real world of limited resources forces a trade-off between collections per se and bibliographic access to information in its broadest sense. The concept of an information resources network may provide a means to manage this plethora of data and of sources. The ability to track the locations of knowledge and of information resources may well prove more valuable to researchers and the university than the necessarily partial collections that libraries can hope to create on-site.

We must beware of assuming linear development through time when we contemplate changing technology and its effect on information. Futurologists like Alvin Toffler assert that the future will be fluid, and will involve multidimensional changes in context that will necessarily preclude straight-line extrapolations and forecasts. The long-term probability of substantially different approaches to information may render many of our current assumptions invalid. "Biotechnology" is but one new field in which there are simultaneous needs to define, create, and create access to, the relevant bibliography; and in which new information technologies will do much to shape the nature of information itself. As knowledge becomes ever more fragile, and as its velocity increases, then the costs of accumulating and publishing it may become prohibitive. Data may eventually be freely stored and exchanged between computers, with hardcopy publications relegated to only a few fields of very particular characteristics. This trend may in fact have begun already, which could explain the decline in publishing output mentioned earlier in the session. The point is not necessarily that the research community will move from print publications to new forms and formats for information, but rather that our planning should allow for nonlinear prog-

*Day Hall is Cornell's administrative headquarters. 
ress. We may need to ask different questions when we anticipate our needs.

In other words, long-term planning should not rest on assumptions of either a static world or one of linear change. On the other hand, and for the near term in which expectations of linear change will conform reasonably well to reality, we need to develop a more sophisticated understanding of the economics of libraries than we now possess. We must therefore address both the allocation problem and the information it requires.

This need can be addressed in at least two ways. The first focuses on the costs of creating and maintaining usable library collections. One can posit that there is an incremental cost attached to every library acquisition. This cost includes the direct purchase price, but must also account for processing, storage, building maintenance, use, and all other relatively invisible elements of overhead. The result would be a more accurate picture than that now available of the how and why of library expenses. And this type of breakdown would allow a more enlightened allocation process within the university administration.

Alternatively, one could cost out the "recovery characteristics" of library acquisitions. Different publications benefit different users, and support different types of use. The delineation of such use characteristics might allow the central administration to justify new, and hopefully more productive, funding mechanisms for the library. For instance, librarians might determine that part of the acquisitions budget is used to build researchoriented collections, that other funds constitute "capital expenditures" for enduring collections, that some money is used to purchase high-turnover books or materials for reserve, and so forth. Different user groups, or beneficiaries, could then be associated with each of these functions. Then, and in contrast to the present practice in which virtually all increases in library budgets are viewed as being paid for through higher tuition bills, the costs of proposed acquisitions could be divided among the real beneficiaries. We may not be able to predict the use that an individ- ual volume will receive, but we must strive to develop large-scale measures that can be integrated within our overall planning and budget mechanisms.

University administrators are indeed tempted to curtail acquisitions budgets in order to limit overall library costs. Some of the blame, though, belongs to librarians who have neither analyzed nor communicated all the costs of their activities. Similarly, and for some of the same reasons, the administration has been conditioned to a mode of dealing with the library that is short-term, response-oriented, and often most aptly characterized as crisis management. A longer-term perspective is essential.

Another element in the university dynamic, to which libraries must adjust, involves changes in programs that in turn imply, or require, changes in acquisitions policies. Not all these changes result in additional expenditures. Cornell's nursing school, for instance, was closed on its hundredth anniversary, and the School of Business and Public Administration is now deciding whether to suspend or eliminate its programs in public and hospital administration.

Most cutbacks are not so visible. Rather, adjustments tend to occur as specific fields receive reduced funding and emphasis within departments or colleges. These shifts are not usually announced, since some degree of subtlety is essential to prevent demoralization or uproar. And these surreptitious shifts may be hard for the library to detect, though informal networks and rumors seem to work reasonably well. In any event, shifts are occurring, and the library must track them and adjust accordingly.

The library should take the lead in developing an information resources network within the university. Librarians possess the skills needed to relate and mediate information while, on the other hand, neither the president nor the provost is likely to command the time and expertise necessary to the task. The library cannot dominate an information resources network, but it can provide leadership both to those managing separate information sources or centers and to the 
information resources network as a whole. For the moment, we need not worry about where money will be found, nor concern ourselves with who ultimately takes charge of a network. We do need to know how the panorama of information is changing. In a longer term, the library should become the "central switching point" in an information resources network.

Thus conclude the viewpoints expressed at this final seminar on the Cor- nell University Libraries' Project for Collection Development and Management. The session was intended as a start as well as a finish: now Cornell's librarians and administrators will begin an open-ended, and not always structured or formal, process of assessing both the broad issues raised in this seminar, and the more specific recommendations of the Concluding Report. The result we all expect is a library system better able to define and to meet its responsibilities in an environment of challenge and change.

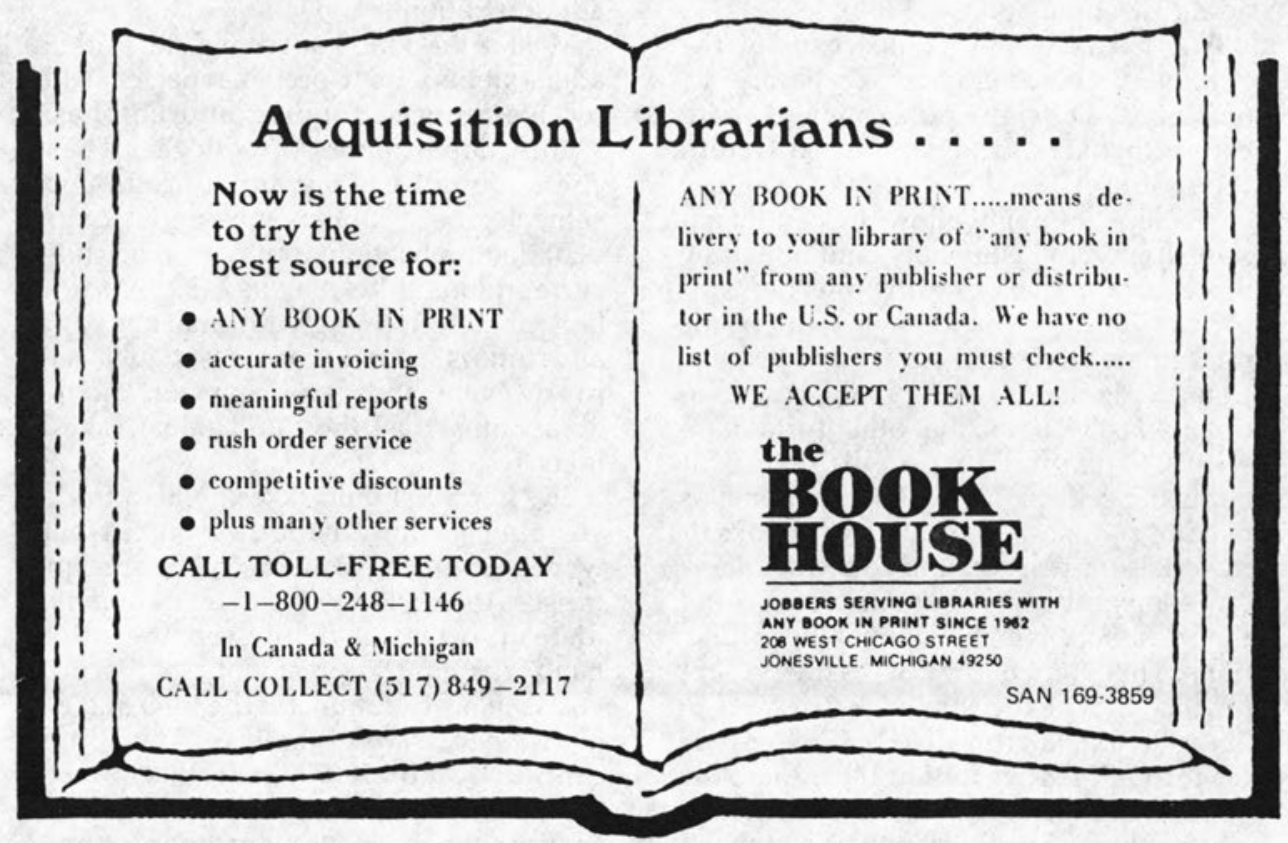

